\title{
Escherichia coli 0111 B4 Lipopolysaccharide Given Intracisternally Induces Blood-Brain Barrier Opening during Experimental Neonatal Meningitis in Piglets ${ }^{1}$
}

\author{
PÉTER TEMESVȦRI, CSONGOR S. ẢBRAHÁM, CHRISTIAN P. SPEER, JÓZSEF KOVẢCS, AND \\ PÁL MEGYERI \\ Department of Pediatrics, Albert Szent-Györgyi Medical University, Szeged, Hungary /P.T., C.S.A.. J.K., P.M.J: \\ and Department of Pediatrics, Georg-August University, Göttingen, Germany /C.P.S.J
}

\begin{abstract}
Neonatal bacterial meningitis remains a lifethreatening infection, and severe neurologic sequelae may be left in survivors as well. The goal of the study was to develop and characterize a porcine model of the disease with intravital observation of the permeability changes in cerebral microvessels. Eighteen newborn piglets were given doses of $0 \mathrm{ng}$ (group 1), $20 \mathrm{ng}$ (group 2), and $200 \mathrm{ng}$ (group 3) of Escherichia coli 0111 B4 endotoxin (LPS) intracisternally ( $n=6$ in each group). Cardiovascular parameters were without changes, but a compensated metabolic acidosis occurred in group $34 \mathrm{~h}$ after LPS injection. Using the open cranial window technique combined with fluorescence excitation, there was no blood-brain barrier leakage in pial-arachnoid microvessels for sodium fluorescein during the $4 \mathrm{~h}$ of experiments in group 1 piglets, whereas spotty extravasations occurred in group 2 and in group 3 after the LPS injections $(70.5 \pm 10.5$ and $55.2 \pm 4.1 \mathrm{~min}$, respectively, mean \pm SEM). A dose-dependent increase in sodium fluorescein uptake in brain regions examined (parietal and occipital cortex, cerebellum, and periventricular white matter) was also found by fluorescence spectrophotometry. LPS-treated piglets had developed pleocytosis. Four $h$ after the challenge, the white blood cell counts in cerebrospinal fluid were (mean \pm SD): group $1,8.2 \pm 7.6$ $\mu L^{-1}$; group $2,453 \pm 703 \mu L^{-1}$; and group 3, $1027 \pm 620$ $\mu \mathrm{L}^{-1}$, respectively, whereas there was no change in white blood cell count of peripheral blood samples. Sixty min after the intracisternal injection, LPS content measured by Limulus amebocytes lysate assay was mildly elevated in cerebrospinal fluid in group 2 and group 3, whereas it was unchanged in sera in either group. We conclude that our model may be appropriate for further in vivo examination of the pathogenesis and treatment of neonatal bacterial meningitis. (Pediatr Res 34: 182-186, 1993)
\end{abstract}

\section{Abbreviations}

BBB, blood-brain barrier

BNU, brain sodium-fluorescein uptake

b.w., body weight

CSF, cerebrospinal fluid

Received April 16, 1992; accepted March 2, 1993.

Correspondence: Dr. P. Temesvári, Department of Pediatrics, Albert SzentGyörgyi Medical University, H-6701 Szeged, P. O. Box 471, Hungary.

Supported by the Hungarian Research Fund OTKA-2699 (P.T.), the Alexander von Humboldt Foundation V-8100 (P.T.), and the Deutsche Forschungsgemeinschaft 239/2-3 (C.P.S.).

'Presented in part at the Annual Meeting of the European Society for Paediatric Research in Zurich, Switzerland, September 1991, and published in abstract form (Pediatr Res 30:648, 1991).

\author{
i.c., intracisternal \\ LPS, lipopolysaccharide \\ $\mathrm{NaF}$, sodium fluorescein \\ WBC, white blood cell \\ $\mathrm{PaCO}_{2}$, arterial carbon dioxide tension \\ EU, endotoxin unit
}

Neonatal bacterial meningitis and its consequences are a major concern for physicians (1). Although many advances have been made in the treatment of the disease, the morbidity and mortality rates attributable remain disturbingly high $(1,2)$.

It is obvious from the previous studies $(3,4)$ of cerebral microvessels on the $\mathrm{BBB}$ that their permeability changes during the disease lead to marked alterations in the extracellular fluid space of the brain, resulting in an abnormal perineuronal milieu and neuronal cell death. Still, many questions remained to be experimentally tested.

In contrast to the large number of data obtained on adult animal models (5-7) and clinical studies (3,4) of bacterial meningitis occurring in childhood, relatively little is known about the specificity of the neonatal infection $(8,9)$. Much of what is known regarding neonatal meningitis has been based upon observations with Haemophilus influenzae in the infant rat (10). There are only a few models in which the newborn animal is given a well-known neonatal pathogen, such as Escherichia coli $(11,12)$, to induce meningeal inflammation.

LPS is one of the major constituents of the outer membrane of gram-negative bacteria. This molecule is a potent toxin and is considered to play a pivotal role in the initiation of the inflammatory cascade involving release of various cytokines and accumulation of leukocytes locally in the site of infection. When injected i.c. into adult rabbits, minute quantities of purified LPS caused disruption of the BBB and brain edema (3).

Because there is a distinct paucity of in vivo observations on the effect of bacterial components on BBB in the newborn period (13), we followed the permeability changes of cerebral microvessels during the early phase of meningeal bacterial infection.

The observation of the pial-arachnoid microvessels using the cranial window technique in newborn piglets is widely accepted for study of the neonatal cerebral circulation in vivo $(13,14)$. The permeability of the BBB can also be followed intravitally by a fluorescence photomacroscope $(15-17)$. The BBB is tight for intravascular tracers physiologically, but certain injuries induce a BBB leakage. The amount of dye extravasated into the cerebral tissue can be determined by fluorescence spectrophotometry (18). The above-mentioned methods are appropriate for both qualitative and quantitative analysis of $\mathrm{BBB}$ permeability. 
The aims of the present study were as follows: $I$ ) to develop a reproducible animal model of neonatal meningitis; 2) to study by the means of the open cranial window technique the intravital permeability changes of cerebral microvessels during infection, and 3) to determine the rate of extravasation through BBB caused by the LPS challenge in different brain regions.

\section{MATERIALS AND METHODS}

Animal preparation. The present study was carried out in 18 piglets of either sex that were between 4 and $8 \mathrm{~h}$ old at the beginning of the experiments and that weighed 1.08 to $1.62 \mathrm{~kg}$. The animals were anesthetized by ketamine hydrochloride (Ketanest. Parke-Davis, Morris Plains, NJ: $10 \mathrm{mg} \times \mathrm{kg}^{-1}$ b.w. intramuscularly). The piglets were tracheatomized and intubated (2.5-3.0 tubes, Portex Ltd.. Hythe. Kent. UK) under local anesthesia (lidocaine hydrochloride, EGIS Ltd.. Budapest. Hungary: $1.0 \mathrm{~mL}, 1.0 \mathrm{vol} \%$ s.c.), paralyzed (pipecuronium bromatum, Arduan, Richter Gedeon Co.. Budapest. Hungary: $0.2 \mathrm{~mL} \times$ $\mathrm{kg}^{-1}$ b.w. i.v.), given $\alpha$-chloralose (Sigma Chemical Co., St. Louis, MO; $30 \mathrm{mg} \times \mathrm{kg}^{-1}$ b.w. $\times \mathrm{h}^{-1}$ i.v.), and artificially ventilated with a conventional, volume-stable. pressure-limited infant respirator (MTA-KUTESZ, Budapest. Hungary). The ventilator parameters were as follows: fraction of inspired oxygen, 0.21 : tidal volume, $1.0-1.6 \times 10^{-2} \mathrm{~L}$ : frequency, $40 \mathrm{~min}^{-1}$; inspiratory time, $0.75 \mathrm{~s}$; peak inspiratory pressure, $1.18-1.48 \mathrm{kPa}(12-15 \mathrm{~cm}$ water): and peak end expiratory pressure. $0 \mathrm{kPa}$. One of the umbilical arteries, the umbilical vein, and the superior vena cava via the jugular vein were catheterized for blood sampling and for giving drugs. Heart rate, mean arterial blood pressure, and central venous pressure were monitored continuously by a Statham P230 transducer. Arterial blood chemistry parameters $(\mathrm{pH}$. standard bicarbonate, $\mathrm{PaCO}_{2}$, and arterial oxygen tension were determined by the standard Astrup method (ABL-330. Radiometer, Copenhagen, Denmark). Proximal airway pressure was monitored. and lung-thorax compliance was calculated by dividing the tidal volume by the insufflation pressure and expressed on the basis of b.w. ( $\mathrm{L} \times \mathrm{Pa}^{-1} \times \mathrm{kg} \mathrm{b.w.)}$. Rectal temperature was kept between 38 and $39^{\circ} \mathrm{C}$.

An open cranial window above the right parietal cortex of piglets was made at stable cardiovascular and blood chemistry parameters. The fluid reservoir of the window was filled under paraffin oil with pyrogen-free artificial CSF $\left(37.5^{\circ} \mathrm{C}\right)$ corresponding to that of the newborn pigs (13). Vasomotor changes of pialarachnoid microvessels were studied, and microphotographs were taken by a Wild M400 photomacroscope and an MPS 55 photoautomat (Heerbrugg, Switzerland) through the window at the different stages of experimental meningitis.

Experimental neonatal meningitis model. A 22-gauge needle was introduced into the cisterna magna of the animals, $0.5 \mathrm{~mL}$ of CSF was slowly withdrawn, and E. coli 0111 B4 LPS (Sigma) diluted with $0.5 \mathrm{~mL}$ of artificial CSF (13) was injected into animals in three groups ( $n=6$ in each). The LPS doses were as follows: group 1, $0 \mathrm{ng}$; group 2, $20 \mathrm{ng}$, and group 3, $200 \mathrm{ng}$. WBC count was determined in blood, and CSF samples were collected before and 120 and $240 \mathrm{~min}$ after the i.c. injection of LPS.

Endotoxin measurement. Commercially available quantitative chromogenic limulus amebocyte lysate assay kits (Coatest, KabiVitrum, Stockholm, Sweden) were used to monitor LPS levels in the plasma and CSF samples, as previously described (19). All glassware, equipment, and pipette tips were pyrogenfree or rendered pyrogen-free by baking at $180^{\circ} \mathrm{C}$ for $4 \mathrm{~h}$. Samples, stored in $-70^{\circ} \mathrm{C}$ until the determinations were performed, were diluted as needed in pyrogen-free water to reach the assay range of $0.1-1.2 \mathrm{EU} \times \mathrm{mL}^{-1}(1 \mathrm{ng}=12 \mathrm{EU})$ in which there is a linear correlation between the absorbance of the E. coli 0111 B4 LPS and endotoxin concentration. Standard dilution series were prepared as controls with each assay. The plasma and CSF samples $(50 \mu \mathrm{L})$ were incubated with an equal volume of limulus ame- bocyte lysate for $10 \mathrm{~min}$ at $37^{\circ} \mathrm{C}$ in sterile 96 -well microtiter plates (Costar, Cambridge, MA). Chromogenic enzyme substrate (S-2423, $100 \mu \mathrm{L}$ ) was then added and incubated for $3 \mathrm{~min}$. The reaction was stopped with $100 \mu \mathrm{L}$ of $25 \%$ acetic acid, and absorbance was read at $405 \mathrm{~nm}$ by a Multiscan plate reader. Final LPS content of the sample was calculated by multiplying the concentration determined from the standard curve by the dilution factor and was expressed as LPS units (EU). All measurements were done in triplicate, and the values were averaged. The lower limit of detection was $0.01 \mathrm{ng}$ of standard endotoxin $\times \mathrm{mL}^{-1}$, equal to $0.11 \mathrm{EU} \times \mathrm{mL}^{-1}$. Inter- and intraassay variability was $<10 \%$.

Assessment of the BBB permeability. Before i.c. injection of different doses of LPS, the animals were given $2 \mathrm{~mL} \times \mathrm{kg}^{-1}$ b.w. (1.0 vol\%) of NaF, a BBB permeability tracer (molecular mass, $376 \mathrm{D}$; Sigma) i.v. in a bolus. Filtered light for fluorescence excitation was provided by a 50 -W mercury lamp and an 12 filter (Leitz, Wetzlar, Germany). In the beginning of the experiments, $\mathrm{BBB}$ proved to be completely tight to $\mathrm{NaF}$ in each preparation. The time elapsed from i.c. injection of LPS until the BBB leakage was recorded in each group. BNU as a quantitative parameter of $\mathrm{BBB}$ permeability was measured according to the method of Trout et al. (18) with minor modifications. Briefly, each animal received a total dose of $10 \mathrm{~mL} \times \mathrm{kg}^{-1} \mathrm{NaF}(1.0 \%)$ in a continuous i.v. infusion during the $4 \mathrm{~h}$ of experiments. Blood samples were taken at the end of experiments, and the piglets were killed by intracardial $\mathrm{KCl}$ injection and perfused with $200 \mathrm{~mL} \times \mathrm{kg}^{-1}$ isotonic saline to remove the intravascularly localized dye. Equal quantities of tissue samples from several brain regions (parietal and occipital cortex, cerebellum, and periventricular white matter) were homogenized in $3.0 \mathrm{~mL}$ of cold $7.5 \%$ trichloroacetic acid and centrifuged at $10000 \times g$ for $10 \mathrm{~min}$. After addition of $0.5 \mathrm{~mL}$ of $5 \mathrm{~N} \mathrm{NaOH}$, the supernatants were analyzed for fluorescein at an excitation wavelength of $440 \mathrm{~nm}$ and an emission wavelength of $525 \mathrm{~nm}$ by a Hitachi $F 2000$ fluorescence spectrophotometer (Tokyo, Japan). The sera $(0.5 \mathrm{~mL})$ were diluted with $0.25 \mathrm{~mL}$ of $15 \%$ trichloroacetic acid, and, after the centrifugation, $0.25 \mathrm{~mL} 5 \mathrm{~N} \mathrm{NaOH}$ was added to the supernatants and the analysis was performed. Freshly prepared $\mathrm{NaF}$ dilution series were used as controls each time. BNU was expressed as $\mu \mathrm{g} \mathrm{NaF} \times(\mathrm{mg} \text { brain tissue })^{-1} / \mu \mathrm{g} \mathrm{NaF} \times(\mu \mathrm{L} \text { serum })^{-1}$.

Statistical analysis. Statistical analysis was performed using $t$ tests. Probability levels $<0.05,<0.01$, and $<0.001$ were considered significant.

The experimental procedures were performed in accordance with the National Institutes of Health guide for the care and use of laboratory animals and were approved by the Ethical Committee on animal investigation, Albert Szent-Györgyi Medical University, Szeged, Hungary (no. 61, ȦTB).

\section{RESULTS}

Cardiovascular and blood chemistry parameters. After i.c. injection of both doses of LPS, the cardiovascular parameters and lung-thorax compliance of the animals (groups 2 and 3) remained in the normal range and did not differ from values measured in control piglets (group 1) during the observation period (data not shown). Although there was no significant change in the acid-base parameters of the piglets in group 2 through the experiments, a significant $(p<0.05)$ metabolic acidosis ( $\mathrm{pH}, 7.24 \pm 0.11 ; \mathrm{HCO}_{3}^{-1}, 17.4 \pm 4.0 \mathrm{mM} \times \mathrm{L}^{-1} ; \mathrm{PaCO}_{2}$, $5.11 \pm 0.85 \mathrm{kPa}$ ) occurred $240 \mathrm{~min}$ after a dose of $200 \mathrm{ng}$ in animals (group 3) compared with both group $1(\mathrm{pH}, 7.30 \pm 0.08$; $\mathrm{HCO}_{3}{ }^{-1}, 21.9 \pm 2.8 \mathrm{mM} \times \mathrm{L}^{-1} ; \mathrm{PaCO}_{2}, 5.80 \pm 0.83 \mathrm{kPa}$ ) and group $2\left(\mathrm{pH}, 7.37 \pm 0.06 ; \mathrm{HCO}_{3}{ }^{-1}, 22.3 \pm 2.0 \mathrm{mM} \times \mathrm{L}^{-1} ; \mathrm{PaCO}_{2}\right.$, $5.67 \pm 0.89 \mathrm{kPa})$. Each value is mean $\pm \mathrm{SD}(n=6)$.

Endotoxin contents and WBC counts in CSF and blood. The endotoxin levels of CSF $60 \mathrm{~min}$ after i.c. injection in group 2 $\left(0.71 \pm 0.09 \mathrm{EU} \times \mathrm{mL}^{-1}, n=6\right)$ and group $3(1.18 \pm 0.11 \mathrm{EU}$ $\left.\times \mathrm{mL}^{-1}, n=6\right)$ were significantly elevated $(p<0.01$ and $p<$ 

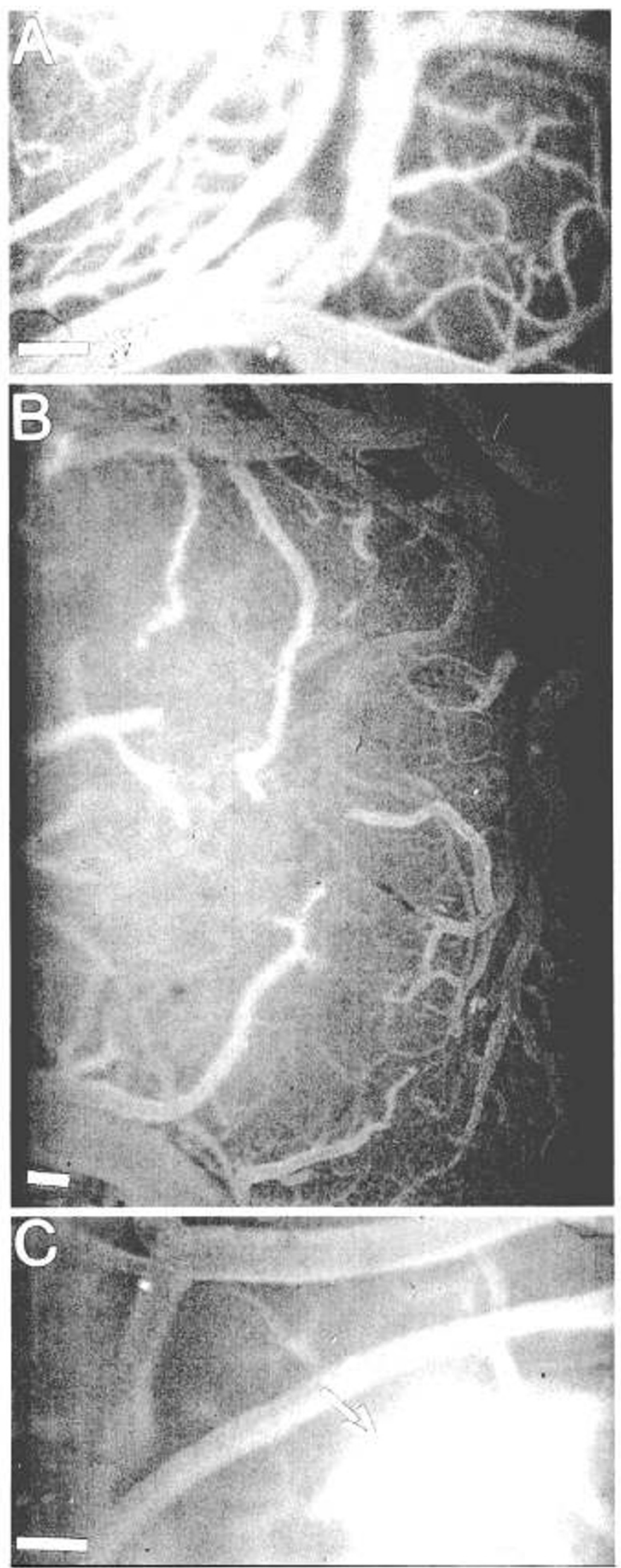

Fig. 1. Fluorescent photodocumentation. Fluorescence microphotographs (bars $=500 \mu \mathrm{m}$ ) of the pial-arachnoid microvessels (intravascular BBB marker was NaF; molecular mass, $376 \mathrm{D}$ ) above the right parietal cortex of newborn piglets were taken after different i.c. challenges. $A$, Two hundred-forty min after the injection of pyrogen-free artificial CSF.
0.001 , respectively) compared with both the basal value $(0.14 \pm$ $0.04 \mathrm{EU} \times \mathrm{mL}^{-1}, n=18$, groups $\left.1-3\right)$ and the concentrations measured in pyrogen-free artificial CSF-treated piglets $(0.17 \pm$ $0.08 \mathrm{EU} \times \mathrm{mL}^{-1}, n=6$, group 1). Each value is mean $\pm \mathrm{SD}$. We could not detect LPS contamination in plasma samples taken at the beginning and the end of experiments (data not shown) in either group of animals. One hundred-twenty and 240 min after the i.c. injection, a significant pleocytosis was seen in the cisternal CSF in both LPS-treated groups (group 2, $186 \pm 122 \mu \mathrm{L}^{-1}$ and $453 \pm 703 \mu \mathrm{L}^{-1}$, respectively; group $3,340 \pm 87 \mu \mathrm{L}^{-1}$ and 1027 $\pm 620 \mu \mathrm{L}^{-1}$, respectively: compared with Group $1(6.4 \pm 3.6$ $\mu \mathrm{L}^{-1}$ and $8.2 \pm 7.6 \mu \mathrm{L}^{-1}$, respectively) values are mean $\pm \mathrm{SD} ; n$ $=6$ in each group. No change developed in peripheral WBC count in either group through the experiments (data not shown).

$B B B$ permeability changes. There was no leakage for $\mathrm{NaF}$ in piglets receiving pyrogen-free artificial CSF (group 1) during $4 \mathrm{~h}$ of observation (Fig. $1 A$ ). Proceeding from intense fluorescence in small venules (Fig. $1 B$ ), distinct leakage sites, defined as a cloud of fluorescent material with a diameter of at least $100 \mu \mathrm{m}$ around a vessel (Fig. 1C), appeared in cerebral microvessels in animals after LPS administration (groups 2 and 3 ). The time needed for the appearance of spotty extravasations after i.c. injections was as follows (mean \pm SEM; $n=6$ in each group): group 2. $70.5 \pm 10.5 \mathrm{~min}$; and group 3. $55.2 \pm 4.1 \mathrm{~min}(p<$ 0.05 ). Figure 2 shows the quantitative evaluation of the $\mathrm{NaF}$ extravasation $4 \mathrm{~h}$ after LPS injection. A marked dose-dependent increase in BNU was found in all regions examined.

\section{DISCUSSION}

For the first time in the literature, we demonstrate here that, at the very early stage of bacterial meningitis, neonatal brain microvessels lose their ability to retain sodium fluorescein intravasally. We observed a dose-dependent increase in the BBB permeability and a decrease in time needed for the BBB opening after i.c. injection of $E$. coli 0111 B4 LPS in newborn piglets. The i.c. challenge also resulted in a significant pleocytosis and increased endotoxin concentrations in CSF, but WBC count in peripheral blood and serum LPS levels remained unchanged during the experiments. There was no change in the cardiovascular and blood-gas parameters, except for a mild, compensated metabolic acidosis in animals $4 \mathrm{~h}$ after the administration of 200 ng of i.c. LPS.

Methodology. The open cranial window technique used here was frequently applied in other animals $(15,16)$ to study in situ certain features of brain microvessels that have, in many respects (hormonal responses, permeability, vasoreactivity), properties similar to the intraparenchymal ones $(15-17,20,21)$. Piglets were chosen because they have become widely used for studying human diseases in the perinatal period. Moreover, open preparations are predisposed to cerebral herniations, particularly in smaller animals such as rabbits (17).

Twenty and $200 \mathrm{ng}$ of i.c. LPS may result in CSF endotoxin concentrations similar to those measured in samples taken from patients suffering from bacterial meningitis $(2,22-24)$, although free LPS levels measured in present experiments $60 \mathrm{~min}$ after the injection were in a lower range. This effect may be originated either in binding of LPS to its receptors localized in CNS or in rapid clearance from cisterna magna by CSF flow. The i.c. endotoxin doses used were calculated to be equivalent to the amounts of LPS present in $2 \times 10^{6}-2 \times 10^{7} \mathrm{E}$. coli organisms (7) and were in the same range as was published for the adult animal models of bacterial meningitis $(3,7)$. In contrast to the previous studies in which i.c. pathogens were given in saline (3,

the indicator remained confined to the intravascular space. $B$. Fifty $\mathrm{min}$ after the i.c. administration of $200 \mathrm{ng}$ of $E$. coli 0111 B4 LPS. intense postcapillary venular fluorescence was seen. C. A cloud of fluorescent material (arrow') around a small venule was observed $58 \mathrm{~min}$ after the injection of $200 \mathrm{ng}$ of LPS. 


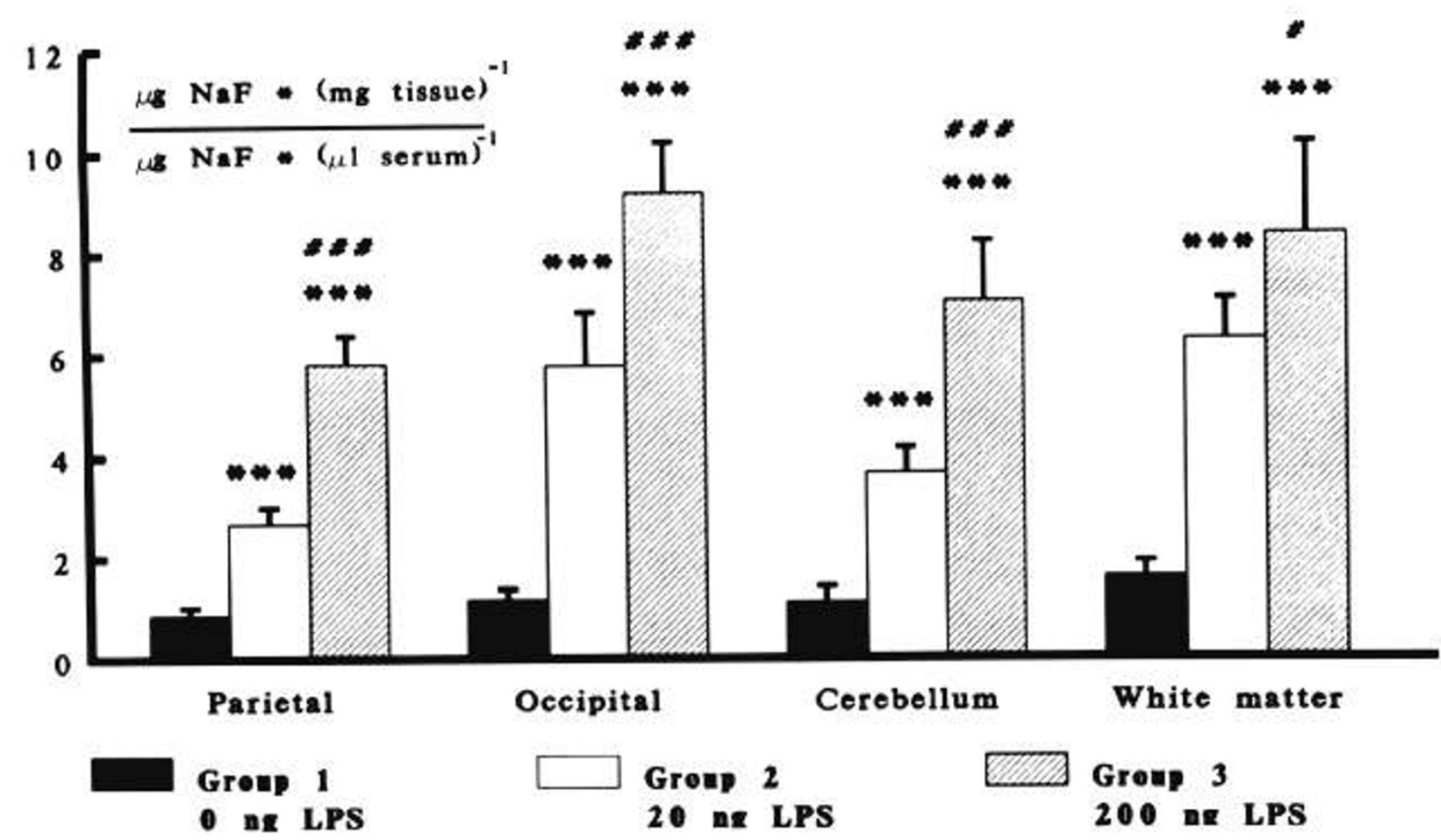

Fig. 2. BNU $4 \mathrm{~h}$ after i.c. injection of LPS (three groups of animals, $n=6$ in each; doses ranging from 0 to $200 \mathrm{ng}$ ). The brain regions examined were parietal and occipital cortex, cerebellum, and periventricular white matter. Values were expressed as $\mu \mathrm{g} \mathrm{NaF} \times(\mathrm{mg} \text { brain tissue })^{-1} / \mu \mathrm{g} \mathrm{NaF} \times$ $(\mu \mathrm{L} \text { serum })^{-1}$, results are means $\pm \mathrm{SEM}$, and the differences were considered significant compared with values measured in group $1\left(^{*} . p<0.05:^{* *}\right.$, $p<0.01 ; * *, p<0.001)$ and group $2(*, p<0.05 ; * * *, p<0.001)$.

7), we diluted the LPS with a species- and age-specific mock CSF to reduce the possibility of an artificial brain injury. Considering all the above-mentioned views, we assume that our neonatal model is similar to the clinical situation and appropriate for studying the changes occurring during bacterial meningitis in newborns.

$B B B$ permeability changes. This is the first in vivo study determining both the time needed for BBB leakage and the quantitative severity of the permeability disturbances of the brain microvasculature during experimentally induced meningeal bacterial infections in newborns. The suitability of pial-arachnoid vessels for the study of BBB function has previously been demonstrated $(15,16,20)$. The affected vessels with increased $\mathrm{NaF}$ permeability are the postcapillary venules, which are the most vulnerable vascular structures with regard to permeability within the CNS and which also behaved similarly to other noxa, such as hypertension, acidosis, and hypoxemia, and to challenge with bradykinin and histamine $(14,15,21)$. In our study, i.c. LPS resulted in a dose-dependent BBB opening for NaF: $200 \mathrm{ng}$ induced more rapid and severe injury than did $20 \mathrm{ng}$. We can assume that plasma components with physicochemical features similar to those of NaF may also extravasate from the cerebral microvessels after i.c. LPS challenge, taking part in the edema formation in the CNS by a compressive effect through the glial elements on the microvasculature. There was no leakage of fluorescent material in the control experiments, in which only mock CSF was given, which shows that the leaks were induced by the exposure.

Although the exact molecular mechanism by which LPS can open the BBB remains to be elucidated, it should be mentioned that products of gram-negative organisms could adhere to the adventitial surface of cerebral capillaries, resulting directly in separation of the tight junctions between endothelial cells and a marked increase in pinocytotic activity within the endothelium. Polymorphonuclear neutrophils augment but it are not essential for this early BBB abnormality $(3,6)$. Previous observations suggest that increased $\mathrm{NaF}$ permeability is associated with an enhanced vesicular transport in brain capillary endothelium (14. $18,25)$. It is also worthwhile to mention that it has been shown that polymyxin $B$, an endotoxin-neutralizing drug, improved the outcome of the experimentally induced bacterial meningitis (26). The enhanced venular fluorescence that preceded the BBB opening could have derived either from endothelial (swelling with $\mathrm{NaF}$ uptake) or from hemorrheologic (adherence of polymorphonuclear neutrophils and thrombocytes to the endothelium) disturbances $(15,22)$.

We found a dose-dependent increase in BNU in four different regions of piglet brain, which suggests a diffuse sensibility to this injury. The same doses, however, induced different BNU: the higher rate in white matter might be due to the increased susceptibility of this region to vasogenic brain edema formation whereas cerebellum and occipital cortex might receive more concentrated LPS solution after i.c. injection than parietal cortex.

The elevation in CSF WBC count developed gradually and followed the rapid $\mathrm{BBB}$ opening for $\mathrm{NaF}$, so we suppose that pleocytosis may play an additional role only in the gross disruption of BBB for larger molecules. The lack of clinically significant systemic effects of LPS is not surprising, as it was given only i.c.

We can conclude that our intravital neonatal meningitis model developed in piglets may be useful in further elucidation of the pathogenesis of the disease and may be appropriate for studying drugs claimed to have a role in its therapy.

Acknowledgment. The authors thank Prof. Ferenc Joo for the critical reading of the manuscript.

\section{REFERENCES}

1. Bell AH. Brown D, Halliday HL, McClure G, McReid M 1989 Meningitis in the newborn: a 14 year review. Arch Dis Child 64:873-874

2. Mustafa MM, Mertsola J, Ramilo O, Sáez-Llorens X, Risser RC, McCracken $\mathrm{Jr}$ GH 1989 Increased endotoxin and interleukin-1 $\beta$ concentrations in cerebrospinal fluid of infants with coliform meningitis and ventriculitis associated with intraventricular gentamicin therapy. J Infect Dis 160:891895

3. Sande MA, Scheld WM. McCracken Jr GH 1987 Report of a workshop: 
pathophysiology of bacterial meningitis: implications for new management strategies. Pediatr Infect Dis J 6:S1167-S1171

4. Sáez-Llorens X, Ramilo O, Mustafa MM. Mertsola J, McCracken Jr GH 1990 Molecular pathophysiology of bacterial meningitis: current concepts and therapeutic implications. J Pediatr 116:671-684

5. Quagliarello VJ, Long WJ. Scheld WM 1986 Morphologic alterations of the blood-brain barrier with experimental meningitis in the rat. Temporal sequence and role of encapsulation. J Clin Invest 77:1084-1095

6. Lesse AJ, Moxon ER, Zwahlen A. Scheld WM 1988 Role of cerebrospinal fluid pleocytosis and Haemophilus influenzae type b capsule on blood brain barrier permeability during experimental meningitis in the rat. $J$ Clin inves 82:102-109

7. Wispelwey B, Lesse AJ, Hansen EJ, Scheld WM 1988 Haemophilus influenzae lipopolysaccharide-induced blood brain barrier permeability during experimental meningitis in the rat. J Clin Invest 82:1339-1346

8. Megyeri P Ảbrahám CS. Temesvári P. Kovács J. Speer CP 1990 TumorNekrose-Faktor $\alpha$ induziert die Öffnung der Blut-Hirn-Schranke: Eine tierexperimentelle Untersuchung. In: Hanefeld F, Rating D. Christen H-J (eds) Actuelle Neuropädiatrie 1989. Springer-Verlag, Berlin-Heidelberg. pp 245248

9. Moxon ER, Glode MP. Sutton A, Robbins JB 1977 The infant rat as a model of bacterial meningitis. J Infect Dis 136:S186-S190

10. Smith AL, Smith DH, Averill Jr DR, Marino J. Moxon ER 1973 Production of Haemophilus influenzae type b meningitis in infant rats by intraperitoneal inoculation. Infect Immun 8:278-290

11. Glode MP, Sutton A, Moxon ER. Robbins JB 1977 Pathogenesis of neonatal Escherichia coli meningitis: induction of bacteremia and meningitis in infant rats fed $E$. coli $\mathrm{K} 1$. Infect Immun 16:75-80.

12. Harper TE, Christensen RD. Rothstein G 1987 The effect of administration of immunoglobulin to newborn rats with Escherichia coli sepsis and meningitis. Pediatr Res 22:455-460

13. Shibata M. Lefler CW. Busija DW 1990 Recombinant human interleukin $1 \alpha$ dilates pial arterioles and increases cerebrospinal fluid prostanoids in piglets. Am J Physiol 259:H1486-H1491

14. Temesvari P. Kovács J 1988 Selective opening of the blood-brain barrier in newborn pielets with experimental pneumothorax Neurosci Lett 93:38-43

15. Wahl M. Unterberg A, Baethmann A 1985 Intravital fluorescence microscopy for the study of blood-brain-barrier function. Int J Microcirc Clin Exp 4:318

16. Joyner WL, Young R, Blank D, Eccleston-Joyner CA, Gilmore JP 1988 In vivo microscopy of the cerebral microcirculation using neonatal allografts in hamsters. Circ Res 63:758-766

17. Schürer L. Kawamura S, Kempski O Goetz A. Baethmann A 1989 The closed cranial window technique for the investigation of blood-brain barrier function and vasomotor control. In: Hammersen F. Messmer K (eds) Cerebral Microcirculation: Progress in Applied Microcirculation, Vol. 16. Karger. Basel, pp 32-41

18. Trout JJ, Koenig H, Goldstone AD, Lu CY 1986 Blood-brain barrier breakdown by cold injury: polyamine signals mediate acute stimulation of endocytosis, vesicular transport, and microvillus formation in rat cerebral capillaries. Lab Invest 55:622-631

19. Arditi M. Ables L. Yogev R 1989 Cerebrospinal fluid endotoxin levels in children with $H$ influenzae meningitis before and after administration of intravenous ceftriaxone. J Infect Dis 160:1005-1011

20. Rapoport SI 1976 Blood-brain barrier in physiology and medicine. Raven Press, New York

21. Wahl M. Unterberg A. Baethmann A. Schilling L 1988 Mediators of bloodbrain barrier dysfunction and formation of vasogenic brain edema. J Cereb Blood Flow Metab 8:621-634

22. McCracken Jr GH, Sarff LD 1976 Endotoxin in cerebrospinal fluid. Detection in neonates with bacterial meningitis. J Am Med Assoc 235:617-620

23. Berman NS, Siegel SE, Nachum R. Lipsey A, Leedom J 1976 Cerebrospinal fluid endotoxin concentrations in gram-negative bacterial meningitis. J Pediatr 88:553-556

24. Mertsola J. Kennedy WA. Waagner D. Sáez-Llorens X. Olsen K. Hansen EJ McCracken Jr GH 1991 Endotoxin concentrations in cerebrospinal fluid correlate with clinical severity and neurologic outcome of Haemophilus influenzae type b meningitis. Am J Dis Child 145:1099-1103

25. Temesvári P. Hencz P. Joó F. Eck E. Szerdahelyi P. Boda D 1984 Modulation of the blood-brain barrier permeability in neonatal cytotoxic brain edema: laboratory and morphological findings obtained on newborn piglets with experimental pneumothorax. Biol Neonate 46:198-208

26. Walterspiel JN, Vitulli WF 1989 Adjunctive treatment with low-dose polymyxin B improves operant response rates and latency in infant rats with Haemophilus influenzae type b meningitis. Pediatr Res 26:496-499 